\section{INFLUÊNCIA DE POLIMORFISMOS NOS GENES ANTIOXIDANTES GSTM1, GSTT1 E GSTP1 NO DESENVOLVIMENTO DE COMPLICAÇÕES OFTALMOLÓGICAS EM DIABÉTICOS TIPO 2}

\section{INFLUENCE OF POLYMORPHISMS IN THE GSTM1, GSTT1, AND GSTP1 ANTIOXIDANT GENES ON THE DEVELOPMENT OF OPHTHALMIC COMPLICATIONS IN PERSONS WITH TYPE 2 DIABETES}

\author{
Aléxia Stefani Siqueira Zetum¹, Mariana Farias Rodrigues ${ }^{1}$, Sávio \\ Paulo dos Santos ${ }^{1}$, Thays de Sousa Santos França ${ }^{1}$, Lorrana Madeira \\ Avelino $^{1}$, Davi Monteiro Godoi ${ }^{1}$, Melissa de Freitas Cordeiro-Silva ${ }^{1}$
}

\begin{abstract}
RESUMO
Introdução: A diabetes tipo 2 (DM2) é uma desordem metabólica ocasionada pela disfunção das células beta pancreáticas que interferem na produção de insulina e/ ou pela resistência dos órgãos alvos a esse hormônio. Níveis elevados de radicais livres em conjunto com o declínio das defesas antioxidantes presente na DM2 podem ocasionar danos a organelas celulares, promovendo complicações da doença. As glutationas S- transferases (GST) são as principais enzimas antioxidantes que participam da defesa celular contra o estresse oxidativo. Os polimorfismos nos genes que codificam essas enzimas podem acarretar o surgimento de complicações oftalmológicas em diabéticos. Este trabalho avaliou a influência dos polimorfismos nos genes GST no desenvolvimento de doenças como a catarata e o glaucoma em pacientes com DM2 na Grande Vitória (ES).
\end{abstract}

Metodologia: Os polimorfismos dos genes GSTM1 e GSTT1 foram investigados através da técnica de PCR multiplex. Para o gene GSTP1 utilizou-se a técnica PCRRFLP. A análise estatística foi realizada através do teste exato de Fisher ou do teste do qui-quadrado com P-valor $<0.05$.

Resultados: Não foi encontrada relação entre os polimorfismos nos genes GSTM1, GSTT1 e GSTP1 e o surgimento de doenças como glaucoma e catarata em pacientes com DM2.

Conclusão: Nossos dados sugerem que os polimorfismos nulos nos genes GSTM1 e GSTT1 e o polimorfismo lle105Val no gene GSTP1 não estão associados com a suscetibilidade individual para o desenvolvimento de complicações oftalmológicas em pacientes com DM2.

Palavras-chave: Estresse oxidativo; Glutationas-S transferases; Polimorfismos genéticos; Radicais livres; Complicações oftalmológicas

\section{ABSTRACT}

Introduction: Type 2 diabetes mellitus (T2DM) is a metabolic disorder caused by beta cell dysfunction that interferes with insulin production and/or by the resistance of target organs to this hormone. An increase in free radicals together with a decline in antioxidant defenses, present in T2DM, can damage cellular organelles and promote the occurrence of disease complications. Glutathione S-transferases (GSTs) are the main antioxidant enzymes involved in cellular defense against oxidative stress, and polymorphisms in genes encoding GSTs can lead to ophthalmic complications in
Clin Biomed Res. 2021:41(2):141-147

1 Centro Universitário Salesiano (UNISALES). Vitória, ES, Brasil.

Autor correspondente: Melissa de Freitas Cordeiro-Silva mcordeiro@salesiano.br Centro Universitário Salesiano (UNISALES)

Avenida Vitória, 950. Forte São João. 29017-950, Vitória, ES, Brasil. 
Zetum et al.

persons with diabetes. In this study, we evaluated the influence of GST polymorphisms on the development of diseases such as cataract and glaucoma in patients with T2DM in Grande Vitória, Espírito Santo, Brazil.

Methods: GSTM1 and GSTT1 polymorphisms were investigated using a multiplex PCR technique. PCR-RFLP was used for the GSTP1 gene. Statistical analysis was performed with Fisher's exact test or the chi-square test, with P-value $<0.05$.

Results: There was no relationship between GSTM1, GSTT1, or GSTP1 polymorphisms and the occurrence of diseases such as glaucoma and cataract in patients with T2DM.

Conclusion: Our data suggest that the GSTM1 and GSTT1 null polymorphisms and the ile105Val polymorphism in the GSTP1 gene are not associated with individual susceptibility to the development of ophthalmic complications in persons with T2DM.

Keywords: Oxidative stress; Glutathione-S-transferase; Genetic polymorphisms; Free radicals; Ophthalmic complications

\section{INTRODUÇÃO}

Diabetes Mellitus tipo 2 (DM2) é um distúrbio metabólico heterogêneo multifatorial ${ }^{1}$ cuja principal característica, a hiperglicemia crônica ${ }^{2}$, é ocasionada pela disfunção das células beta pancreáticas que afetam a produção de insulina e/ou pela resistência dos órgãos alvos a esse hormônio provocando um aumento da glicose no sangue ${ }^{3}$. Atualmente, 463 milhões de pessoas possuem Diabetes Mellitus no mundo 4 e no Brasil, aproximadamente 16,8 milhões de indivíduos possuem a $\mathrm{DM}^{4}$, sendo que, $90 \%$ desses casos correspondem a Diabetes Mellitus tipo $2^{5}$.

Estima-se que fatores genéticos contribuam cerca de $30 \%$ a $70 \%$ para o surgimento da doença $a^{6-7}$. Diversos polimorfismos nos genes responsáveis pela produção das enzimas desintoxicantes vem sendo associados ao surgimento da $\mathrm{DM} 2^{8}$, esses polimorfismos influenciam no aumento do estresse oxidativo, sendo relacionado a resistência a insulina, disfunção das células beta pancreáticas e diminuição da tolerância à glicose ${ }^{9}$.

O estresse oxidativo, é caracterizado pelo desequilíbrio entre radicais livres e defesas antioxidantes ${ }^{10}$. $\mathrm{Na}$ Diabetes Mellitus tipo 2 há a diminuição das defesas antioxidantes e um aumento na produção de espécies reativas de oxigênios (EROS), relacionado a maiores chances de desenvolver complicações secundárias como problemas oftalmológicos ${ }^{11}$. O excesso de EROS resulta na degradação e agregação de proteínas nas lentes oculares, sendo considerado um importante fator no surgimento de doenças como a catarata e o glaucoma ${ }^{12,13}$.

As células apresentam sistemas de defesas que ajudam a controlar a produção excessiva de EROS. Dentre as defesas antioxidantes, as glutationas S- transferases (GSTs) GSTM1, GSTT1 e GSTP1 são as principais enzimas que participam da defesa celular contra o estresse oxidativo ${ }^{14}$.

As GSTs pertencem a uma superfamília de enzimas $^{15}$ e os genes GSTM1, GSTT1 e GSTP1, responsáveis pela produção dessas enzimas, são polimórficos em humanos e, diversos estudos associam variações desses genes ao aumento do risco de certas doenças incluindo a DM2 $2^{14,16,17}$.

Dentre os GSTs, os genes GSTM1 e GSTT1 podem apresentar polimorfismo de deleção, que quando em homozigose acarretam na falta de isoformas ativas, conhecida como genótipo nulo ${ }^{18-20}$. O GSTT1- nulo é encontrado em frequências que variam entre 11 a 38\% dependendo da população, nesse caso, ocorre a deleção de $50 \mathrm{~kb}$ da sequência do gene. Para o GSTM1 nulo, são excluídos $15 \mathrm{~kb}$ da sequência e sua frequência varia de 20 a $70 \%$ entre as populações ${ }^{1,18,21}$.

Em relação ao GSTP1, os seus alelos variantes são encontrados com bastante frequência entre as populações, e é caracterizado pelo polimorfismo único de nucleotídeo ( $S N P$ ) no qual, ocorre uma substituição da base adenina (A) para guanina $(G)$, resultando na transição de isoleucina para valina no códon 105 (lle105Val)22. Estudos anteriores já demonstraram a correlação entre esses polimorfismos e o surgimento de complicações oftalmológicas ${ }^{23-25}$.

As GSTs são encontradas em diversas estruturas oculares, como o corpo cristalino, ciliar e o humor aquoso ${ }^{26}$. Polimorfismos nos genes GSTs vem sendo associados com maior risco de desenvolvimento de glaucoma e catarata, visto que, essas variações genéticas alteram as funções antioxidantes das enzimas, diminuindo sua proteção contra o EROS afetando diretamente as células oculares ${ }^{25}$. Ademais, pacientes com DM2 apresentam atividade antioxidante reduzida em suas lentes oculares ${ }^{27}$. Dessa forma, estudos sugerem que o sistema GST pode estar relacionado diretamente a suscetibilidade individual a doenças oculares na DM2.

O objetivo deste artigo foi avaliar a influência dos polimorfismos nos genes GSTM1, GSTT1 e GSTP1 no desenvolvimento de complicações oftalmológicas em pacientes com DM2 da Grande Vitória/ES. 


\section{MATERIAL E MÉTODOS}

\section{Grupo Amostral}

O estudo incluiu 102 indivíduos diagnosticados com Diabetes tipo 2, atendidos entre março de 2017 a setembro de 2019, na Associação de Diabéticos de Vila Velha/ES, no Centro Integrado de Atenção à Saúde da Católica (CIASC) e na Unidade de Saúde Dr Bolívar de Abreu, Forte São João, Vitória/ES, Brasil.

Esse trabalho foi aprovado pelo Comitê de Ética em Pesquisa do Centro Universitário Salesiano UniSales. Número do parecer: 2.353.462. Todos os participantes assinaram o termo de consentimento livre e esclarecido.

\section{Análise Molecular}

O DNA genômico foi isolado de leucócitos de sangue periférico através do método orgânico utilizando-se Fenol/Clorofórmio. Os polimorfismos dos genes GSTM1 e GSTT1 foram investigados através da técnica de PCR multiplex ${ }^{22}$, utilizando um fragmento de $340 \mathrm{pb}$ do gene CYP1A1 como controle interno de amplificação. O polimorfismo no gene GSTP1 foi detectado pela técnica de PCR-RFLP ${ }^{28}$. As sequências dos oligonucleotídeos iniciadores (primers), a enzima de restrição utilizada na técnica PCR-RFLP e o tamanho dos produtos obtidos encontram-se na Tabela 1. Os fragmentos obtidos foram submetidos à eletroforese horizontal em gel de agarose $2 \%$.

Tabela 1: Sequências dos primers, enzima de restrição e tamanhos dos produtos obtidos.

\begin{tabular}{clcc}
\hline GENE & \multicolumn{1}{c}{ PRIMER 5' - 3' } & ENZIMA DE RESTRIÇÃO & PRODUTO GERADO (pb) \\
\hline \multirow{2}{*}{ GSTM1 } & F: GAACTCCCTGAAAAGCTAAAGC & & \\
& R: GTTGGGCTCAAAT ATACGGTGG & N.A. & $215 \mathrm{pb}$ \\
GSTT1 & F: TTCCTTACTGGTCCTCACATCTC & & \\
& R: TCACCGGATCATGGCCAGCA & N.A. & $480 \mathrm{pb}$ \\
CYP1A1 & F: TAGGAGTCTTGTCTCATGCCT & & $340 \mathrm{pb}$ \\
& R: CAGTGAAGAGGTGTAGCCGCT & N.A. & Alelo normal: $176 \mathrm{~b}$ \\
GSTP1 & F: ACCCCAGGGCTCTATGGGAA & BsmAl & Alelo variante: $83 \mathrm{pb}$ e $93 \mathrm{pb}$ \\
\hline
\end{tabular}

N.A.: Não Aplicado.

\section{Análise Estatística}

As comparações entre os grupos em variáveis categóricas foram realizadas utilizando o teste exato de Fisher ou o teste do qui-quadrado usando o software GRAPHPAD PRISM V5. Foi considerado significante P-valor $<0.05$.

\section{RESULTADOS}

Inicialmente foram divididos dois grupos gerais, o de indivíduos com alguma complicação oftalmológica (COF) e os indivíduos que não apresentavam nenhuma complicação (SOF). O estudo incluiu 102 pacientes, sendo $39(38,2 \%)$ com alguma complicação oftalmológica e $63(61,8 \%)$ sem. No grupo com complicações observa-se o predomínio do gênero feminino $(66,6 \%)$ com idade média de 66 anos. Não houve diferença significativa entre os grupos supracitadas quanto a idade $(p>0,9999)$ e gênero $(p=0,5365)$.

Referente a distribuição genotípica entre os grupos estudados, a prevalência de GSTM1, GSTT1 e GSTP1 está representando na tabela 2. As amostras foram separadas em subgrupos possuindo indivíduos com e sem glaucoma e/ou catarata. Dentre os indivíduos pertencentes ao grupo da catarata que possuíam a doença, 59,4\% apresentaram genótipo nulo para o gene GSTM1 e $40,6 \%$ possuíam genótipo presente. Em relação ao gene GSTT1, o genótipo nulo correspondeu a 15,6\% enquanto o genótipo presente equivale a $84,4 \%$. GSTP1 ile/ile foi o mais frequente $(50 \%)$ seguido por Ile/Val $(40,6 \%)$ e por fim Val/Val $(9,4 \%)$. Conforme a tabela 2, não foi encontrada relevância estatística nesse subgrupo para os genes GSTM1 $(p=0,1371)$, GSTT1 ( $p>0,9999)$ e GSTP1 ( $p=0,9184)$. No que concerne aos indivíduos do subgrupo do glaucoma, quando avaliados frente a presença ou ausência da doença, verificou-se que $5 \%$ dos pacientes possuíam genótipo nulo para o gene GSTM1, enquanto $7 \%$ para o genótipo presente. Para o gene GSTT1, a frequência encontrada entre a amostra estudada foi de $3 \%$ para o genótipo nulo e $9 \%$ para o genótipo presente. Para o gene GSTP1, a variante ile/ile foi a mais frequente $(6 \%)$. A análise estatística revelou valor de $p=0,7652$ para GSTM1, de $p=0,3875$ para GSTT1 e $p=0,6677$ para GSTP1, logo, não houve relevância significativa entre os genes estudados no subgrupo do glaucoma (Tabela 2 ). 
Zetum et al.

Tabela 2: Distribuição genotípica entre os grupos estudados.

\begin{tabular}{|c|c|c|c|c|c|c|c|c|}
\hline \multirow{2}{*}{ Genótipos } & \multicolumn{2}{|c|}{ GG } & \multicolumn{2}{|c|}{ CATARATA } & \multirow{2}{*}{ pValue } & \multicolumn{2}{|c|}{ GLAUCOMA } & \multirow{2}{*}{ pValue } \\
\hline & N. & (\%) & S (\%) & N (\%) & & S (\%) & $N(\%)$ & \\
\hline \multicolumn{9}{|l|}{ GSTM1 } \\
\hline Nulo & 49 & 48,0 & $19(19,0)$ & $29(29,0)$ & $p=0,1371$ & $5(5,1)$ & $41(41,8)$ & $p=0,7652$ \\
\hline Presente & 53 & 52,0 & $13(13,0)$ & $39(39,0)$ & & $7(7,1)$ & $45(45,9)$ & \\
\hline \multicolumn{9}{|l|}{ GSTT1 } \\
\hline Nulo & 16 & 15,7 & $5(5,0)$ & $11(11,0)$ & $p>0,9999$ & $3(3,0)$ & $12(12,2)$ & $p=0,3875$ \\
\hline Presente & 86 & 84,3 & $27(27,0)$ & $57(57,0)$ & & $9(9,1)$ & $74(75,5)$ & \\
\hline \multicolumn{9}{|l|}{ GSTP1 } \\
\hline lle/lle & 49 & 48,0 & $16(16,0)$ & $31(31,0)$ & & $6(6,1)$ & $41(41,8)$ & \\
\hline Ile/Val & 43 & 42,1 & $13(13,0)$ & $30(30,0)$ & $p=0,9184$ & $4(4,0)$ & $37(37,7)$ & $p=0,6677$ \\
\hline $\mathrm{Val} / \mathrm{Val}$ & 10 & 9,8 & $3(3,0)$ & $7(7,0)$ & & $2(2,0)$ & $8(8,1)$ & \\
\hline Ile/Val+ Val/Val & 53 & 51,9 & $16(16,0)$ & $37(37,0)$ & & $6(6,0)$ & $45(45,8)$ & \\
\hline
\end{tabular}

GG: Grupo Geral; S: Sim; N: Não.

Na Tabela 3 está representado a frequência de distribuição com genótipos combinados. A combinação dupla dos genes GSTM1 e GSTT1 no subgrupo da catarata e no subgrupo do glaucoma estão apresentados, entretanto, a combinação desses dois genótipos não demonstrou relação com as doenças supracitadas, uma vez que não fora achado relevância estatística para nenhum dos genótipos analisados até mesmo quando houve combinação polimórfica de ambos os genes $(p=0,2901 / 0,6194)$. A distribuição da frequência com combinação tripla entre os genes GSTM1, GSTT1 e GSTP1 estão expressos também na Tabela 3. A combinação tripla dos genótipos não demonstrou relação com a presença das complicações oftalmológicas.

Tabela 3: Características genéticas dos pacientes com glaucoma e catarata.

\begin{tabular}{|c|c|c|c|c|}
\hline \multirow{2}{*}{ GENÓTIPO } & CATARATA & \multirow{2}{*}{ pValue } & GLAUCOMA & \multirow{2}{*}{ pValue } \\
\hline & S (\%) N (\%) & & S (\%) N (\%) & \\
\hline GSTM1/GSTT1 & $13(13,0) 34(34,0)$ & referencial & $6(6,1) 41(41,8)$ & referencial \\
\hline GSTM1 nulo/GSTT1 nulo & $5(5,0) 6(6,0)$ & $P=0,2901$ & $2(2,0) 8(8,1)$ & $P=0,6194$ \\
\hline GSTM1 presente/GSTT1 nulo & $0(0,0) 5(5,0)$ & $P=0,3143$ & $1(1,0) 4(4,0)$ & $P=0,5299$ \\
\hline GSTM1 nulo/GSTT1presente & $14(14,0) 23(23,0)$ & $P=0,3543$ & $3(3,0) 33(33,6)$ & $P=0,7251$ \\
\hline \multicolumn{5}{|l|}{ GSTP1/GSTT1/GSTM1 } \\
\hline Ile/lle/presente/presente & $6(6,0) 16(16,0)$ & referencial & $3(3,0) 19(19,3)$ & referencial \\
\hline Ile/Ile/nulo/nulo & $3(3,0) 3(3,0)$ & $P=0,3518$ & $1(1,0) 5(5,1)$ & $P>0,9999$ \\
\hline Ile/Ile/nulo/presente & $7(7,0) 11(11,0)$ & $P=0,5092$ & $2(2,0) 16(16,3)$ & $P>0,9999$ \\
\hline Ile/lle/presente/nulo & $0(0,0) 1(1,0)$ & $P>0,9999$ & $0(0,0) 1(1,0)$ & $P>0,9999$ \\
\hline Ile/Val/nulo/nulo & $2(2,0) 1(1,0)$ & $P=0,2313$ & $1(1,0) 1(1,0)$ & $P=0,3116$ \\
\hline Ile/Val/nulo/presente & $6(6,0) 12(12,0)$ & $P=0,7385$ & $1(1,0) 16(16,3)$ & $P=0,6180$ \\
\hline Ile/Val/presente/nulo & $0(0,0) 3(3,0)$ & $P=0,5539$ & $0(0,0) 3(3,0)$ & $P>0,9999$ \\
\hline Ile/Val/presente/presente & $5(5,0) 14(14,0)$ & $p>0,9999$ & $2(2,0) 17(17,3)$ & $P>0,9999$ \\
\hline Val/Val/nulo/nulo & $1(1,0) 2(2,0)$ & $p>0,9999$ & $0(0,0) 2(2,0)$ & $p>0,9999$ \\
\hline Val/Val/nulo/presente & $1(1,0) 0(0,0)$ & $P=0,3043$ & $0(0,0) 1(1,0)$ & $p>0,9999$ \\
\hline Val/Val/presente/nulo & $0(0,0) 1(1,0)$ & $p>0,9999$ & $1(1,0) 0(0,0)$ & $P=0,1739$ \\
\hline Val/Val/presente/presente & $2(2,0) 4(4,0)$ & $p>0,9999$ & $1(1,0) 5(5,1)$ & $p>0,9999$ \\
\hline
\end{tabular}




\section{DISCUSSÃO}

Com este estudo avaliou-se a possível relação entre complicações oftalmológicas em pacientes da Grande Vitória/ES portadores da Diabetes Mellitus tipo 2 com polimorfismos em genes de enzimas antioxidantes GSTM1, GSTT1 e GSTP1, responsáveis por uma das defesas do organismo contra o estresse oxidativo.

Os grupos analisados apresentaram-se homogêneos quanto a gênero e idade $(p=0,5365$ e $p>0,9999)$, observou-se um predomínio do sexo feminino no grupo com complicações oftalmológicas. Conforme a última pesquisa publicada pelo sistema de vigilância de fatores de risco e proteção para doenças crônicas por inquérito telefônico ${ }^{29}$, a Diabetes possui maior prevalência no sexo feminino e este distúrbio é um fator que aumenta as chances de complicações oftalmológicas graves como a catarata e o glaucoma ${ }^{30}$.

A catarata é uma doença multifatorial e o estresse oxidativo em conjunto com fatores genéticos são considerados os principais envolvidos no desenvolvimento da doença ${ }^{31}$. Neste estudo, a presença do gene GSTM1 nulo não foi associado com o risco de desenvolvimento da catarata em pacientes diabéticos $(p=0,1371)$. Em uma metanálise desenvolvida por Sun e colaboradores ${ }^{32}$ quando analisado de forma geral sem a presença da diabetes, não fora encontrada associação entre desenvolvimento da doença com o GSTM1 nulo na população caucasiana ( $p=0,443$ ), entretanto, encontraram associação na população asiática $(p=0,039)$.

A presença do genótipo nulo do gene GSTT1 em pacientes diabéticos não foi relacionada com a catarata neste estudo $(p>0,9999)$. Liao e colaboradores ${ }^{33}$, ao analisar a relação do gene GSTT1 com a catarata sem considerar possíveis doenças associadas, concluíram que a presença do polimorfismo deste gene não contribuiu para maiores chances de desenvolvimento da doença na população caucasiana $(p=0,474)$ porém no mesmo estudo, encontravam relevância estatística na população asiática $(p=0,003)$.

Não houve relevância estatística entre o polimorfismo no gene GSTP1 e a catarata ( $p=0,9184)$, entretanto, trabalhos como o de Juronen e colaboradores ${ }^{23}$ descreveram que a presença de GSTP1 val/val é um fator importante para o desenvolvimento da catarata cortical, em contraste, no mesmo estudo, GSTP1 ile/ile apresentou função protetora contra a doença. Existem muitos fatores que podem justificar os resultados distintos, entre eles, a abrangência do estudo, a quantidade da amostra estudada, a metodologia, entre outros.

Assim como na catarata, fatores de riscos para o desenvolvimento do glaucoma precisam ser elucidados. Neste estudo, não fora encontrada relação entre o genótipo GSTM1 nulo em diabéticos e a incidência de glaucoma $(p=0,7652)$. Em uma meta análise realizada por Huang e colaboradores ${ }^{34}$ ao analisar a influência do GSTM1 nulo no desenvolvimento do glaucoma na população caucasiana e mestiça, não demonstraram qualquer associação significativa entre os polimorfismos do gene e a doença. Contudo, Rocha e colaboradores ${ }^{35}$ encontraram uma maior frequência do genótipo GSTM1 nulo em pacientes que possuíam glaucoma.

Não houve relevância significativa entre o GSTT1 nulo e o glaucoma ( $p=0,3875)$. Resultados semelhantes foram relatados nos trabalhos de Yldirim e outros ${ }^{24}$ e os de Izzotti e colaboradores ${ }^{36}$. Também não observou-se associação para o gene GSTP1 e o glaucoma, no mesmo estudo de Yldirim e outros também não fora encontrada tal relação. A literatura sugere que os genes GSTT1 e GSTP1 podem não estar associados ao maior risco de desenvolvimento do glaucoma.

As diferenças encontradas podem refletir as origens genéticas e étnicas entre as populações analisadas. Além disso, métodos utilizados e a quantidade da amostra podem ser responsáveis pela discordância entre os achados. Ademais, a população brasileira possui um alto grau de miscigenação e isso pode ser outra explicação para resultados obtidos ${ }^{37}$.

Quando combinados os genótipos GSTM1 e GSTT1, não foi achado relevância estatística para a catarata, entretanto, trabalhos anteriores como o de Sireesha e outros ${ }^{38}$ demonstraram que indivíduos que apresentavam a combinação de GSTM1 nulo e GSTT1 nulo possuíam maiores chances de desenvolvimento da doença. Já em um estudo na população chinesa, houve uma associação entre a combinação do genótipo GSTM1 presente e GSTT1 nulo com maior chance de desenvolvimento de catarata Cortical ${ }^{39}$.

Quanto ao glaucoma, Rasool e colaboradores ${ }^{40}$ observaram que a combinação do genótipo nulo GSTM1 com o genótipo positivo para o GSTT1 tende a diminuir o risco de desenvolver essa doença na população egípcia. Na população turca, foi demonstrado que a combinação entre o GSTM1 positivo e o GSTT1 nulo podem estar associados a um maior risco de desenvolvimento do glaucoma ${ }^{25}$.

Nós examinamos combinações específicas da variante dos genótipos GSTM1, GSTT1 e GSTP1 nos pacientes diabéticos, entretanto, não encontramos qualquer relação com o desenvolvimento das doenças. A combinação do genótipo GSTM1 nulo, GSTT1 presente e GSTP1 ile/val foi verificada anteriormente por estudos como o do Çelik e outros ${ }^{41}$ que, sem restringir a amostra a pacientes com diabetes, encontraram uma associação entre esses três genótipos combinados e um maior risco de desenvolvimento da catarata na população da Turquia.

Rykov e colaboradore s $^{42}$ relataram que a combinação dos genótipos GSTP1 (Val/Val) * GSTM1 nulo e GSTT1 positivo pode ser um fator de risco para o 
desenvolvimento do estágio inicial do glaucoma. A combinação GSTP1 (ile/ile) *GSTM1 nulo*GSTT1 nulo foi associado com a progressão da doença, contudo, no mesmo estudo, as combinações GSTP1(Ile/ Ile) ${ }^{*}$ GSTM1 presente GSTT1 presente, GSTP1(lle/ Ile) ${ }^{*}$ GSTM1 presente*GSTT1-nulo e GSTP1(lle/lle) ${ }^{*}$ GSTM1-nulo *GSTT1 presente foram considerados protetores contra a progressão da doença.

Embora muitos estudos já tenham demonstrado a relação entre o estresse oxidativo e o desenvolvimento de complicações da Diabetes, como a catarata e o glaucoma ${ }^{43-45}$, é válido lembrar que outros fatores podem contribuir para o estresse oxidativo além das variações genéticas nas enzimas antioxidantes GSTs avaliadas no presente estudo, como alterações em outros genes de enzimas que atuam na desintoxicação, por exemplo, a catalase, glutationa peroxidase, superóxido dismutase, além dos fatores exógenos como hábitos de vida que propiciem o aumento da produção de EROS. Dessa forma, é provável que haja outros mecanismos que atuem na indução de complicações oftalmológicas na população estudada e isso implica na necessidade de novas estratégias de estudo, como ampliar o painel de polimorfismos genéticos avaliados ${ }^{46}$.

Nossos dados sugerem que os polimorfismos nulos nos genes GSTM1 e GSTT1 e o polimorfismo lle105Val no gene GSTP1 não estão associados com a suscetibilidade individual para o desenvolvimento de problemas oftalmológicos em pacientes com DM2.

\section{Agradecimentos}

Agradecemos ao Centro Integrado de Atenção a Saúde da Católica (CIASC), a Associação de Diabéticos de Vila Velha/ES e a Unidade de saúde Dr Bolívar de Abreu. Aos voluntários que participaram desse estudo. A Fundação de Amparo à Pesquisa e Inovação do Espírito Santo (FAPES) e ao Programa de Iniciação e Pesquisa Científica do UniSales pelo apoio financeiro.

\section{REFERÊNCIAS}

1. Pinheiro DS, Costa C, Rocha Filho C, 7. Bonnefond A, Durand E, Sand O, Mundim C, Reis A, Ghedini P. Avaliação do nível de controle glicêmico dos pacientes diabéticos tipo 2 atendidos em um hospital universitário. Rev Univ Vale Rio Verde. 2013;10:3-11.

2. Ogurtsova K, Fernandes JDR, Huang Y, Linnenkamp U, Guariguata L, Cho NH, et al. IDF Diabetes Atlas: Global estimates for the prevalence of diabetes for 2015 and 2040. Diabetes Res Clin Pract. 2017;128:40-50.

3. Al-Kharashi AS. Role of oxidative stress, inflammation, hypoxia and angiogenesis in the development of diabetic retinopathy. Saudi J Ophthalmol. 2018;32(4):318-23.

4. International Diabetes Federation. IDF Diabete Atlas: 9th edition 2019 [Internet]. Bruxelas; 2019 [citado 25 set 2020]. Disponível em: https:// www.diabetesatlas.org/en/sections/ worldwide-toll-of-diabetes.html

5. Sociedade Brasileira de Diabetes. Diretrizes da Sociedade Brasileira de Diabetes 2019-2020. São Paulo: Clannad; 2019.

6. Doria A, Patti ME, Kahn CR. The emerging genetic architecture of type 2 diabetes. Cell Metab. 2008;8(3):186-200.
De Graeve F, Gallina S, Busiah K et al. Molecular diagnosis of neonatal diabetes mellitus using next-generation sequencing of the whole exome. PLoS One. 2010;5(10):e13630.

8. Kajimoto $\mathrm{Y}$, Kaneto $\mathrm{H}$. Role of Oxidative Stress in Pancreatic $\beta$-Cell Dysfunction. Ann N Y Acad Sci. 2004;1011:168-76.

9. West IC. Radicals and oxidative stress in diabetes. Diabet Med. 2000;17(3):171-80.

10. Barbosa K, Costa N, Alfenas R, De Paula S, Minim V, Bressam J. Oxidative stress: concept, implications and modulating factors. Rev Nutr. 2010 [citado 12 out 2021];23(4):629-43.

11. Fridlyand LE, Philipson LH. Reactive species and early manifestation of insulin resistance in type 2 diabetes. Diabetes Obes Metab. 2006;8(2): 136-45.

12. Aslan M, Cort A, Yucel I. Oxidative and nitrative stress markers in glaucoma. Free Radic Biol Med. 2008;45(4): 367-76.

13. Babizhayev MA. Mitochondria induce oxidative stress, generation of reactive oxygen species and redox state unbalance of the eye lens leading to human cataract formation: disruption of redox lens organization by phospholipid hydroperoxides as a common basis for cataract disease. Cell Biochem Funct. 2011;29(3):183-206.

14. Ansolin P, Damin D, Alexandre C. Polymorphism of glutathione $\mathrm{s}$-transferase $\mathrm{m} 1, \mathrm{t} 1$ and $\mathrm{p} 1$ and association with clinicopathological aspects in colorectal carcinoma. Rev Bras Coloproctol. 2010;30:281-8.

15. Wang G, Zhang L, Li Q. Genetic polymorphisms of GSTT1, GSTM1, and NQO1 genes and diabetes mellitus risk in Chinese population. Biochem Biophys Res Commun. 2006;341(2):310-3.

16. Ramprasath $T$, Senthil Murugan $P$, Prabakaran AD, Gomathi P, Rathinavel A, Selvam GS. Potential risk modifications of GSTT1, GSTM1 and GSTP1 (glutathioneS-transferases) variants and their association to CAD in patients with type-2 diabetes. Biochem Biophys Res Commun. 2011;407(1):49-53.

17. Amer MA, Ghattas MH, Abo-Elmatty DM, Abou-El-Ela SH. Evaluation of glutathione S-transferase $\mathrm{P} 1$ genetic variants affecting type-2 diabetes susceptibility and glycemic control. Arch Med Sci. 2012;8(4):631-6.

18. Arruda VR, Grignolli CE, Gonçalves MS, Soares MC, Menezes R, Saad ST, et al. Prevalence of homozygosity for the deleted alleles of glutathione S-transferase mu (GSTM1) and 
theta (GSTT1) among distinct ethnic groups from Brazil: relevance to environmental carcinogenesis? Clin Genet. 1998;54(3):210-4.

19. Koch FP, Kämmerer PW, Kämmerer $P$, Al-Nawas B, Brieger J. Influence of class M1 glutathione S-transferase (GST Mu) polymorphism on GST M1 gene expression level and tumor size in oral squamous cell carcinoma. Oral Oncol. 2010;46(2):128-33.

20. Reis AA, Silva DM, Curado MP, Da Cruz AD. Involvement of CYP1A1, GST, 72TP53 polymorphisms in the pathogenesis of thyroid nodules. Genet Mol Res. 2010;9(4):2222-9.

21. Doney AS, Lee S, Leese GP, Morris AD, Palmer CN. Increased cardiovascular morbidity and mortality in type 2 diabetes is associated with the glutathione $S$ transferase thetanull genotype: a Go-DARTS study. Circulation. 2005;111(22):2927-34.

22. Bid HK, Konwar R, Saxena M, Chaudhari P, Agrawal CG, Banerjee M. Association of glutathione S-transferase (GSTM1, $\mathrm{T} 1$ and $\mathrm{P} 1$ ) gene polymorphisms with type 2 diabetes mellitus in north Indian population. J Postgrad Med. 2010;56(3):176-81.

23. Juronen E, Tasa G, Veromann S, Parts L, Tiidla A, Pulges R,et al. Polymorphic glutathione S-transferases as genetic risk factors for senile cortical cataract in Estonians. Invest Ophthalmol Vis Sci. 2000;41(8):2262-7.

24. Yildirim O, Ateş NA, Tamer L, Oz O, Yilmaz A, Atik U, Camdeviren H. May glutathione S-transferase M1 positive genotype afford protection against primary open-angle glaucoma? Graefes Arch Clin Exp Ophthalmol. 2004;243(4):327-33.

25. Unal M, Güven M, Devranoğlu K, Ozaydin A, Batar B, Tamçelik N, et al. Glutathione S transferase M1 and $\mathrm{T} 1$ genetic polymorphisms are related to the risk of primary open-angle glaucoma: a study in a Turkish population. $\mathrm{Br} \mathrm{J}$ Ophthalmol. 2006;91(4):527-30.

26. Wilkinson J, Clapper M. Detoxication enzymes and chemoprevention. Exp Biol Med. 1997;216(2):192-200.

27. Kiziltoprak H, Tekin K, Inanc M, Goker YS. Cataract in diabetes mellitus. World J Diabetes. 2019;10(3):140-53.
28. Stoian A, Bănescu C, Bălaşa RI, Moţă̌̆ăianu A, Stoian M, Moldovan VG, et al. Influence of GSTM1, GSTT1, and GSTP1 Polymorphisms on Type 2 Diabetes Mellitus and Diabetic Sensorimotor Peripheral Neuropathy Risk. Dis Markers. 2015;2015:638693.

29. Brasil, Ministério da Saúde. Vigilância de fatores de risco e proteção para doenças crônicas por inquérito telefônico (VIGITEL). Estimativas sobre frequência e distribuição sociodemográfica de fatores de risco e proteção para doenças crônicas nas capitais dos 26 estados brasileiros e no distrito federal. Brasília, DF; 2018.

30. Henriques J, Vaz-Pereira S, Nascimento J, Rosa PC. Doença Ocular Diabética. Acta Med Port. 2015;28(1):107-13.

31. Gupta VB, Rajagopala M, Ravishankar B. Etiopathogenesis of cataract: an appraisal. Indian J Ophthalmol. 2002;62(2):103-10.

32. Sun L, Xi B, Yu L, Gao XC, Shi DJ, Yan YK, et al. Association of glutathione S-transferases polymorphisms (GSTM1 and GSTT1) with senile cataract: a metaanalysis. Invest Ophthalmol Vis Sci. 2010;51(12):6381-6.

33. Liao RF, Ye MJ, Liu CY, Ye DQ. An Updated Meta-Analysis: Risk Conferred by Glutathione S-Transferases (GSTM1 and GSTT1) Polymorphisms to AgeRelated Cataract. J Ophthalmol. 2015;2015:103950.

34. Huang W, Wang W, Zhou M, Chen S, Zhang $X$. Association of glutathione S-transferase polymorphisms (GSTM1 and GSTT1) with primary open-angle glaucoma: an evidence-based metaanalysis. Gene. 2013;526(2):80-6.

35. Rocha AV, Talbot T, Magalhães da Silva T, Almeida MC, Menezes CA, Di Pietro G, Rios-Santos F. Is the GSTM1 null polymorphism a risk factor in primary open angle glaucoma? $\mathrm{Mol}$ Vis. 2011;17:1679-86.

36. Izzotti A, Saccà SC, Cartiglia C De Flora S. Oxidative deoxyribonucleic acid damage in the eyes of glaucoma patients. Am J Med. 2003;114(8):638-46.

37. Lordelo GS, Miranda-Vilela AL, Akimoto AK, Alves PC, Hiragi CO, Nonino A, et al. Association between methylene tetrahydrofolate reductase and glutathione S-transferase M1 gene polymorphisms and chronic myeloid leukemia in a Brazilian population. Genet Mol Res. 2012;11(2):1013-26.

38. Sireesha R, Laxmi SG, Mamata M, Reddy PY, Goud PU, Rao PV, et al. Total activity of glutathione-Stransferase (GST) and polymorphisms of GSTM1 and GSTT1 genes conferring risk for the development of age related cataracts. Exp Eye Res. 2012;98:67-74.

39. Jiang Z, Liang K, Zhang Q, Tao L. Glutathione S-transferases polymorphisms confer susceptibility to senile cortical cataract in the Han Chinese population. Mol Vis. 2012;18:1247-52.

40. Rasool H, Nowier S, Gheith M, Saif $A$, Ismail $S$. The risk of primary open angle glaucoma and glutathione $s$ transferase $\mathrm{m} 1$ and $\mathrm{t} 1$ polymorphism among egyptians. J Am Sci. 2010;6(12):375-81.

41. Çelįk SK, Aras N, Yildirim Ö, Turan F, Görür A, Yildirim $H$, et al. Glutathione S-transferase GSTM 1, null genotype may be associated with susceptibility to age-related cataract. Adv Clin Exp Med. 2015;24(1):113-9.

42. Rykov O, Natrus, L, Burdey A. Association of ile $105 \mathrm{val}$ polymorphism of gstp1 gene with primary open-angle glaucoma. Arch Ukr Ophthalmol. 2018;6(1):40-5.

43. Zorić L. Neki parametri oksidacionog stresa u socivu, ocnoj vodici i serumu bolesnika sa diabetesom i senilnom kataraktom. Srp Arh Celok Lek. 2003;131(3-4):137-42.

44. Hashim Z, Zarina S. Osmotic stress induced oxidative damage: possible mechanism of cataract formation in diabetes. J Diabetes Complications. 2012;26(4):275-9.

45. Miric DJ, Kisic BB, Zoric LD, Mitic RV, Miric BM, Dragojevic IM. Xanthine oxidase and lens oxidative stress markers in diabetic and senile cataract patients. J Diabetes Complications. 2012;27(2):171-6.

46. Qi R, Gu Z, Zhou L. The effect of gstt1, gstm1 and gstp1 gene polymorphisms on the susceptibility of age-related cataract in chinese han population. Int J Clin Exp Med. 2015;8(10):19448-53. 